\title{
URINARY TRACT INFECTIONS; ETIOLOGICAL PROFILE AND ANTIMICROBIAL SUSCEPTIBILITY PAT- TERNS OF UROPATHOGENS
}

1. Assistant Professor, Department of Pathology, Frontier Medical \& Dental College, Abbottabad.

2. Assistant Professor Department of Medicine, Frontier Medical \& Dental College, Abbottabad.

3. Senior Lecturer,

Mohi Ud Din Islamic Medical College, Mirpur, Azad Kashmir.

4. Professor,

Department of Pathology, Frontier Medical \& Dental College, Abbottabad.

Corresponding Author: Dr. Muhammad Usman Anjum Assistant Professor,

Department of Pathology,

Frontier Medical \& Dental College, Abbottabad.

usmanziyai@gmail.com

Article received on: 05/08/2015

Accepted for publication:

15/10/2015

Received after proof reading:

$13 / 01 / 2016$

\section{Dr. Muhammad Usman Anjum¹, Dr. Muhammad Safdar Khan², Dr. Abdul Razzaq Shahid³,} Dr. Syed Humayun Shah ${ }^{4}$

ABSTRACT... Background: Urinary tract infections (UTIS) constitute important bacterial disease which contributes to significant morbidity world-wide. Empirical treatment in patients suffering from UTI depends upon the local knowledge of common microorganisms responsible for UTI in that geographical area as well as their antimicrobial susceptibility patterns. Objectives: To determine the frequency and antimicrobial susceptibility of uropathogens which are responsible for urinary tract infections. Study Design: Experimental study. Setting: Department of Pathology, Frontier Medical \& Dental College and Mohi Ud Din Islamic Medical College. Period: January 2015 to June 2015. Material \& methods: Total of 113 patients were included in the study. Urine samples were cultured on MacConkey's agar and Cysteine Lactose Electrolyte Deficient (CLED) agar. Micro-organisms were identified using standard tests and antimicrobial susceptibility was checked using modified Kirby Bauer method following Clinical and Laboratory Standards Institute (CLSI) guidelines. Results: The average age of patients was 32.19 \pm 16.47 years. Gram negative organisms accounted for majority of cases, about 89 $(78.76 \%)$ cases. Escherichia coli was the most common micro-organism which was found in $50(44.24 \%)$ cases followed by Staphylococcus aureus in 24 (21.24\%), Enterobacter spp. in 19 (16.81\%), Klebsiella spp. in 11 (9.73\%) and Proteus spp. in 9 (7.96\%) cases. E. coli was sensitive to imipenem and ciprofloxacin and was resistant to amoxicillin/clavulanic acid and gentamicin. Conclusion: Gram negative organisms are largely responsible for UTIs and E. coli being the most common etiological agent. $\mathrm{E}$. coli is sensitive to commonly prescribed drugs for UTI like ciprofloxacin.

Key words: $\quad$ Urinary tract infection, antimicrobial sensitivity, E. coli.

Article Citation: Anjum MU, Khan MS, Shahid AR, Shah SH. Urinary tract infections; etiological profile and antimicrobial susceptibility patterns of uropathogens. Professional Med J 2016;23(1):010-014. DOI: 10.17957/TPMJ/16.3044

\section{INTRODUCTION}

Urinary tract infections (UTIs) constitute important bacterial disease which contributes to significant morbidity in both out-patient and in-patients. ${ }^{1,2}$ UTIs lead to significant healthcare expenditure which amounts to 1.6 billion dollars each year in United States of America. ${ }^{3} \mathrm{UTI}$ affects both sexes but is more common in women. The increased incidence of UTI in females is attributed to many factors like short urethra, proximity of urethra to anal area and hence, increased risk of infection by fecal flora. ${ }^{4}$ UTI can affect any part of urinary system and usually presents with painful mictuirition, foul smelling urine, loin pain and urgency. ${ }^{4}$ Urine microscopy and culture are of paramount importance in the diagnosis of UTIs. ${ }^{5}$

UTIs are caused by different pathogens but most common among them are bacteria, which are responsible for about $95 \%$ of cases. ${ }^{6}$ Among bacterial pathogens, Enterobacteriaceae family is an important cause of UTI with Escherichia coli accounting for $70-80 \%$ of cases. ${ }^{2,6}$ Other bacterial pathogens responsible for UTI include Klebsiella pneumoniae, Pseudomonas aeruginosa ${ }_{1}$ Proteus spp. and Enterococcus spp. ${ }^{2,4,7}$ Uropathogens are developing resistance to many commonly prescribed antibiotics at an alarming rate. ${ }^{8}$ Routine diagnostic and culture facilities are not available in many parts of developing countries and it results in incorrect diagnosis or self-medication which contribute significantly to the development of antimicrobial resistance among uropathogens. . $^{1,9}$ Therefore, it is of vital importance to know the etiological profile and antibiotic susceptibility patterns of uropathogens in a geographical 
location to guide treatment decisions for patients suffering from UTIs.

The aim of our study was to determine the common etiological organisms in patients suffering from UTI and their antimicrobial susceptibility patterns in Abbottabad, Pakistan.

\section{MATERIALS \& METHODS}

This study was conducted in the Department of Pathology, Frontier Medical \& Dental College and Mohi Ud Din Islamic Medical College, from January 2015 to June 2015. It was an experimental study and there was a nonprobability consecutive sampling. All patients of both genders who were more than 20 years of age and suspected of having UTI were included in this study. The patients having recurrent UTIs, with urological abnormalities, those on antibiotics and pregnant women were excluded from the study. Based on inclusion and exclusion criteria, 113 samples were collected.

The clean catch mid-stream urine (MSU) sample was collected in a sterile wide mouthed container and processed immediately. A drop of urine sample was placed on a clean slide for microscopy and observed for the presence of white blood cells (WBC). Presence of $\geq$ 10 WBCs per high per field was considered significant. ${ }^{10}$ The urine samples were inoculated on MacConkey's agar (Oxoid, UK), Cysteine Lactose Electrolyte Deficient (CLED) agar (Oxoid, UK) and Blood agar (Oxoid, UK) at $37^{\circ} \mathrm{C}$ for 2448 hours. A bacterial growth of $\geq 10^{5} \mathrm{cfu} / \mathrm{ml}$ was considered significant. Organisms were identified on the basis of colony morphology, gram staining and biochemical characteristics.

The antibiotic susceptibility of bacterial isolates was tested using modified Kirby Bauer disc diffusion method following Clinical and Laboratory Standards Institute (CLSI) guidelines. Zones of inhibitions were measured. The commercially available antibiotic susceptibility discs (Oxoid, UK) were used. They included; Amoxicillin/ clavulanic acid $(20 / 10 \mu \mathrm{g})$, Cefotaxime $(5 \mu \mathrm{g})$, Ciprofloxacin $(5 \mu \mathrm{g})$, Trimethoprim/sulfamethoxazole
$(1.25 / 23.75 \mu \mathrm{g})$, Gentamicin $(30 \mu \mathrm{g})$, Ceftriaxone $(30 \mu \mathrm{g})$, Amikacin $(30 \mu \mathrm{g})$ and Imipenem $(10 \mu \mathrm{g})$.

Statistical Package for Social Sciences (SPSS, version 17) was used for statistical analysis. Mean, standard deviation was calculated for descriptive variables like age and percentages for antimicrobial susceptibility.

\section{RESULTS}

There were 113 patients with 64 males and 49 females with male to female ratio of $1.31: 1$, as shown in Figure-1. The average age of patients was $32.19 \pm 16.47$ years.

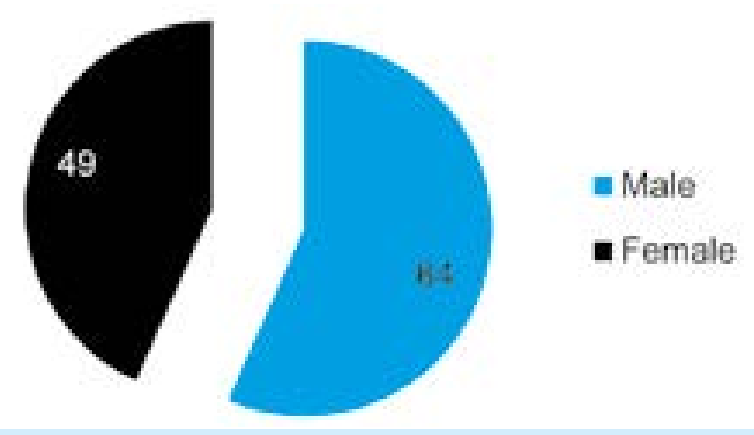

Figure-1. Gender-wise distribution of study sample

The number of gram negative micro-organisms responsible for UTI was quite higher than gram positive organisms as shown in Table-I.

\begin{tabular}{|c|c|}
\hline Pathogens & No of cases,(Percentage) \\
\hline Gram Negative Organisms & $89,(78.76 \%)$ \\
\hline Gram Positive Organisms & $24,(21.24 \%)$ \\
\hline Total & $113,(100 \%)$ \\
\hline
\end{tabular}

Table-I. Distribution of microorganisms according to gram staining, $(n=113)$

Frequency of different microorganisms causing UTI was shown in Table-II. E. coli was the most common microorganism isolated. It was isolated from $50(44.24 \%)$ cases followed by S. aureus which was found in 24 (21.24\%) while Klebsiella spp. and Proteus spp. were the least common, being isolated in $11(9.73 \%)$ and 9 (7.96\%) patients respectively.

Sensitivity of different microorganisms (in 
percentages) to different antibiotics is shown in Table-III. E. coli showed higher sensitivity to imipenem and ciprofloxacin and was resistant to amoxicillin/clavulanic acid, S. aureus was sensitive to ciprofloxacin and resistant to cefotaxime, Enterobacter spp. were sensitive to amoxicillin/clavulanic acid, ciprofloxacin and ceftriaxone while highly resistant to cefotaxime, Klebsiella spp. were sensitive to gentamicin and trimethoprim/sulfamethoxazole while resistant to cefotaxime and amikacin and Proteus spp. were sensitive to amikacin, ciprofloxacin and amoxicillin/clavulanic acid while resistant to cefotaxime and imipenem.

\begin{tabular}{|c|c|}
\hline Microorganism & No of cases \\
\hline Escherichia coli & $50,(44.24 \%)$ \\
\hline Staphylococcus aureus & $24,(21.24 \%)$ \\
\hline Enterobacter spp. & $19,(16.81 \%)$ \\
\hline Klebsiella spp. & $11,(9.73 \%)$ \\
\hline Proteus spp. & $09,(7.96 \%)$ \\
\hline Total & $113,(100 \%)$ \\
\hline Table-II. Distribution of microorganisms responsible \\
\hline \multicolumn{2}{|r}{ for UTI, (n=113) } \\
\hline
\end{tabular}

\begin{tabular}{|c|c|c|c|c|c|c|c|c|}
\hline Microorganism & $\begin{array}{c}\text { Amoxicillin/ } \\
\text { clavulanic acid }\end{array}$ & Cefotaxime & Ciprofloxacin & $\begin{array}{c}\text { Trimethoprim/ } \\
\text { sulfamethoxazole }\end{array}$ & Gentamicin & Ceftriaxone & Amikacin & Imipenem \\
\hline E. coli & $28 \%$ & $56 \%$ & $66 \%$ & $40 \%$ & $44 \%$ & $52 \%$ & $64 \%$ & $76 \%$ \\
\hline S. aureus & $54.16 \%$ & $20.83 \%$ & $79.17 \%$ & $54.17 \%$ & $75 \%$ & $54.17 \%$ & $54.17 \%$ & $41.67 \%$ \\
\hline $\begin{array}{c}\text { Enterobacter } \\
\text { spp. }\end{array}$ & $94.74 \%$ & $0 \%$ & $84.76 \%$ & $73.68 \%$ & $57.90 \%$ & $84.21 \%$ & $57.89 \%$ & $57.89 \%$ \\
\hline Klebsiella spp. & $27.27 \%$ & $18.18 \%$ & $54.54 \%$ & $72.11 \%$ & $81.81 \%$ & $54.54 \%$ & $18.18 \%$ & $63.63 \%$ \\
\hline Proteus spp. & $88.89 \%$ & $0 \%$ & $100.00 \%$ & $77.78 \%$ & $77.78 \%$ & $66.67 \%$ & $88.87 \%$ & $0.00 \%$ \\
\hline
\end{tabular}

\section{DISCUSSION}

UTIs are one of the main causes of seeking medical attention. ${ }^{2}$ Empirical therapy in these patients depends upon the knowledge of microorganisms prevalent in that area as well as their antimicrobial sensitivity patterns. ${ }^{11}$ This study was conducted to determine the frequency of different uropathogens which are responsible for UTIs and their antimicrobial sensitivity patterns. Our study has shown that there was higher predilection for male gender. This is in contrast to findings of other studies done on the same subject. ${ }^{12,13}$ It could be due to highly conservative nature of population in our area where female patients either don't seek medical care or they prefer to visit female doctors. The average age of patients was $32.19 \pm 16.47$ years. This finding was comparable to other studies.

A study done in Palestine by Zakariya el Astal reported mean age to be $31.6 \pm 10.3$ years. ${ }^{14}$ Similarly, a study done in Pakistan by Khan et al and another done in Iran by Kashef et al reported it to be 48 years and 48.5 years respectively. 2,10

The incidence of gram negative uropathogens was higher in our study. It was $78.76 \%$. This is similar to other studies done in our region. Baral et al, in their study conducted in Nepal, and Farajnia et al, in their study which was conducted in Iran, also reported the prevalence of gram negative organisms to be $95.4 \%$ and $85.6 \%$ respectively. ${ }^{1,6}$

E. coli (44.24\%) was found to be the most common microorganism causing UTI in our study. Our findings corroborated with other studies. Khan et al and Shahzad et al documented the incidence of $\mathrm{E}$. coli to be $61.3 \%$ \& $68.1 \%$ respectively in Pakistan, Das et al documented it to be $59.4 \%$ in Nepal, Al-haddad documented it to be $41.5 \%$ in Yemen and Kashef et al reported it to be 68.8 $\%$ in Iran. ${ }^{2,4,5,10,15}$ The incidence of Klebsiella spp. was $9.73 \%$ and that of Proteus spp. to be $7.96 \%$ in our study. Kashef et al, in their study conducted in Iran, reported their incidence to be $9.6 \%$ and $12.4 \%$ while Das et al, in their study conducted in Nepal, reported it to be $15.7 \%$ and $7.4 \%$ respectively. ${ }^{10,12}$ Our study has shown that the frequency of S. aureus was $21.24 \%$. This is in contrast to other studies. Shahzad et al reported the incidence of $\mathrm{S}$. aureus to be $11.5 \%$ while Das et al to be $3.4 \%$ respectively. ${ }^{4,12}$ This difference 
may be due to differing patterns of incidence of uropathogens in different geographical locations.

Our study has shown that among gram negative urinary isolates, E. coli was sensitive to imipenem, amikacin and ciprofloxacin. It was considerably resistant to amoxicillin/clavulanic acid. Klebsiella spp. were sensitive to imipenem and gentamicin while resistant to cefotaxime and amikacin. Proteus spp. were sensitive to ciprofloxacin, amoxicillin/clavulanic acid and amikacin while resistant to cefotaxime and imipenem. Both Klebsiella spp. and Proteus spp. were sensitive to trimethoprim/sulfamethoxazole. This is quite in common with the findings of other studies. A study from India by Niranjan and Malini reported higher resistance of $\mathrm{E}$. coli to amoxicillin/ clavulanic acid in their study. ${ }^{16}$ Khan et al also reported the same finding in their study where E. coli was sensitive to amikacin and imipenem and resistant to amoxicillin/clavulanic acid while Klebsiella spp. were sensitive to imipenem. ${ }^{2}$ Das et al, in their study from Nepal, documented the same finding where Proteus spp. were sensitive to amikacin and ciprofloxacin. ${ }^{5}$

Regarding gram positive organisms, our study has shown that $S$. aureus was sensitive to ciprofloxacin and gentamicin while resistant to cefotaxime and imipenem. Enterobacter spp. were sensitive to amoxicillin/clavulanic acid, ciprofloxacin and ceftriaxone while resistant to cefotaxime. Shahzad et al have also showed the same results where $\mathrm{S}$. aureus was sensitive to ciprofloxacin. ${ }^{4}$ We have reported an interesting finding that both gram positive organisms in our study were resistant to cefotaxime, which was commonly used as parenteral treatment of UTI. This may be due to injudicious use of these antibiotics which lead to increased resistance among uropathogens.

In conclusion, our study has shown that gram negative organisms are responsible for more cases of UTI and E. coli is the main causative agent. E. coli is sensitive to commonly prescribed drugs, like ciprofloxacin, amikacin and imipenem. Copyright(C)15 Oct, 2015.

\section{REFERENCES}

1. Baral P, Neupane S, Marasini BP, Ghimire KR, Lekhak B, Shrestha $B$. High prevalence of multidrug resistance in bacterial uropathogens from Kathmandu, Nepal. BMC Research Notes. 2012;5:38-46.

2. Khan IU, Mirza IA, Ikram A, Afzal A, Ali S, Hussain A, et al. Antimicrobial susceptibility pattern of bacteria isolated from patients with urinary tract infection. Journal of the College of Physicians and Surgeons Pakistan. 2014;24(11):840-4.

3. Vasquez Y, Hands WL. Antibiotic susceptibility patterns of community-acquired urinary tract infection isolates from female patients on the US (Texas)-Mexico border. Journal of Applied Research. 2004;4(2).

4. Shahzad KA, Ullah F, Muhammad K, Khatoon F, Qazi $M$, Ahmed I. Multiple drug resistance patterns in urinary tract infection patients in Peshawar, Khyber Pukhtunkhwa (KPK) Pakistan. Journal of Infection and Molecular Biology. 2013;1(4):67-70.

5. Das R, Chandrashekhar T, Joshi H, Gurung M, Shrestha $\mathrm{N}$, Shivananda P. Frequency and susceptibility profile of pathogens causing urinary tract infections at a tertiary care hospital in western Nepal. Singapore Medical journal. 2006;47(4):281-5.

6. Farajnia S, Alikhani MY, Ghotaslou R, Naghili B, Nakhlband $A$. Causative agents and antimicrobial susceptibilities of urinary tract infections in the northwest of Iran. International Journal of Infectious Diseases. 2009;13(2):140-4.

7. Hooton TM, Besser R, Foxman B, Fritsche TR, Nicolle LE. Acute uncomplicated cystitis in an era of increasing antibiotic resistance: a proposed approach to empirical therapy. Clinical Infectious Diseases. 2004;39(1):75-80.

8. Gupta K. Addressing antibiotic resistance. American Journal of Medicine. 2002;113(Suppl1A):S29-S34.

9. Hammer DA, Dongol S, Anderson TP, Wong JS, Werno AM, Murdoch DR. High prevalence of extended-spectrum beta-lactamase-producing Enterobacteriaceae in Nepal. International Journal of Antimicrobial Agents. 2007;30(5):471-2.

10. Kashef N, Djavid GE, Shahbazi S. Antimicrobial susceptibility patterns of community-acquired uropathogens in Tehran, Iran. The Journal of Infection in Developing Countries. 2010;4(4):202-6.

11. Anjum M, Shams N, Hussain S, Shah S. Bacteriological profile and antibiotic susceptibility of blood isolates in blood stream infections. Medical Forum. 


\section{5;26(2):32-6.}

12. Dash M, Padhi S, Mohanty I, Panda P, Parida B. Antimicrobial resistance in pathogens causing urinary tract infections in a rural community of Odisha, India. Journal of Family and Community Medicine. 2013;20(1):20-6.

13. Bano K, Khan J, Begum R, Munir S, Akbar N, Ansari $\mathrm{JA}$, et al. Patterns of antibiotic sensitivity of bacterial pathogens among urinary tract infections (UTI) patients in a Pakistani population. African Journal of Microbiology Research. 2012;6(2):414-20.
14. El Astal Z. Increasing ciprofloxacin resistance among prevalent urinary tract bacterial isolates in Gaza strip, Palestine. Journal of Biomedicine and Biotechnology. 2005;2005(3):238-41.

15. Al-Haddad AM. Urinary tract infection among pregnant women in Al-Mukalla district, Yemen. Eastern Mediterranean Health Journal. 2005;11(3):505-10.

16. Niranjan V, Malini A. Antimicrobial resistance pattern in Escherichia coli causing urinary tract infection among inpatients. Indian Journal of Medical Research. 2014;139(6):945-8.

\section{PREVIOUS RELATED STUDY}

Ghulam Hussain Baloch, Mukhtiar Hussain Jaffery, Chandra Madhudas, Bikha Ram Devrajani, Syed Zulfiqar Ali Shah. URINARY TRACT INFECTION; FREQUENCY AND PATTERN IN PATIENTS WITH DIABETES MELLITUS (Original) Prof Med Jour 18(3) 466-469 Jul, Aug, Sep 2011.

Zahoor Ullah, Mir Hassan Khan, Tasleem Akhtar, Salar Zai, Javed Ahmad. URINARY TRACT INFECTION; AN OLD DISEASE IN THE NEW AGE (Original) Prof Med Jour 12(2) 166-169 Apr, May, Jun, 2005

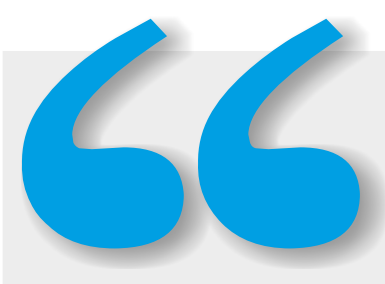

\section{“The happiest people don't have best of everything, they make best of everything."}

\section{Unknown}

\section{AUTHORSHIP AND CONTRIBUTION DECLARATION}

\begin{tabular}{|c|l|}
\hline Sr. \# & \multicolumn{1}{|c|}{ Author-s Full Name } \\
\hline 1 & Dr. M. Usman Anjum \\
2 & Dr. M. Safdar Khan \\
3 & Dr. Abdul Razzaq Shahid \\
4 & Dr. Syed Humayun Shah \\
\hline
\end{tabular}

\author{
Contribution to the paper \\ Written manuscript \& \\ performed study \\ Performed study / co-author \\ Performed study / co-author \\ Conceived the idea, \\ supervised and proof-read \\ the manuscript
}

Author $=$ s Signature

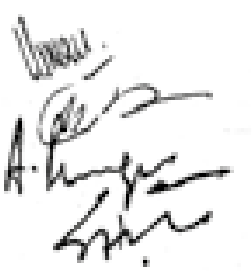

